\title{
A Randomized Controlled Trial Exploring the Effect of Music on Quality of Life and Depression in Older People with Dementia
}

\begin{abstract}
This randomized controlled trial investigated the effect of live music on quality of life and depression in 47 older people with dementia using the Dementia Quality of Life and Geriatric Depression Scale. The control/reading group reported higher mid-point feelings of belonging than the music group $(F(1,45)=6.672, p<0.05)$. Sub-analyses of $\geq 50 \%$ music session attendance found improvements in self-esteem over time $(F(2,46)=4.471, p<0.05)$. Participants with scores that were suggestive of increased depressive symptoms had fewer depressive symptoms over time $(F(2,22)=8.129$, $p<0.01$ ). Findings suggest music and reading activities can improve self-esteem, belonging and depression in some older people with dementia.
\end{abstract}

\section{Key Words}

Dementia, Quality of Life, Depression, Older People, Music

\section{Acknowledgements}

This paper reports on an outcome of a larger study funded by the National Health \& Medical Research Council, Australia (Grant ID 481929). The authors acknowledge support and contributions by RSL Care staff, family and residents. 
Dementia is an umbrella term used to describe a group of conditions which result in progressive decline of a person's cognitive functioning, broadly affecting memory, intellect, social skills and ability to learn. It is a degenerative condition, usually occurring in older age, but not necessarily so, and is typically characterised by the emergence of behavioural disturbances such as agitation, aggression, wandering and confusion (Goodall \& Etters, 2005). Current estimates suggest that there are approximately 24.3 million people who experience dementia worldwide, with an estimated 4.6 million new cases diagnosed each year (Ferri et al., 2005). In Australia, it is estimated that there are currently 245,400 people with dementia and this is predicted to rise to 1.13 million cases by 2050 (Access Economics, 2009). Collectively, these estimates present a concerning backdrop for healthcare in Australia, and worldwide. As such, there is a pertinent need for a better understanding of the ways in which the mental health and quality of life in individuals with dementia can be reduced.

Traditionally, symptoms of dementia have been managed by pharmacological interventions and physical restraints (Robinson et al., 2007). However, recent research has suggested that many of the commonly used pharmacological agents do not offer the desired 'magic pill' solution (Sink, Holden \& Yaffe, 2005). For instance, although the benefits of some pharmacological agents, such as atypical antipsychotics (i.e., risperidone and olanzapine), in treating neuropsychiatric symptoms in those with dementia is well documented, there is also evidence which reports that some of the agents cause physical problems, such as cognitive impairment, constipation, urinary retention and an increase in falls (Leibovici, 2009). In addition to this, are growing ethical concerns regarding the use of physical restraints (Hughes, 2002), with reports showing that they can increase the risk of serious injury, falls and even death (Evans, 
Woods and Lambert, 2003). In light of this, research attempts have become more focused on understanding the efficacy of non-pharmacological treatment (Goodall \& Etters, 2005), albeit these studies have generally suffered from small sample sizes and weak methodologies (Cohen-Mansfield \& Mintzer, 2005). The therapeutic use of music is one such intervention and has gained increasing popularity since the early 1990’s (Bruer, Spitznagel \& Cloninger, 2007).

Defined as 'the specialized use of music to change maladaptive physical, emotional and social behaviour to attain maximum levels of functioning' (Goodall \& Etters, 2005 p.258), the therapeutic use of music is generally regarded as offering a means of communicating, with those with dementia (Goodall \& Etters, 2005). It is thought that, as the person's ability to understand verbal language diminishes (Vink, Birks, Bruinsma \& Scholten, 2005), the ability to process music is retained by a part of the brain that is last to deteriorate (Crystal, Grober \& Masur, 1989). Individual studies and meta-analyses into the efficacy of music for managing dementia have reported it as a successful intervention, with a wide range of positive outcomes and, seemingly, a lack of side effects (Svansdottri \& Snaedal, 2006). For instance, music has been shown to improve cognitive functioning (Bruer, Spitznagel \& Cloninger, 2007; Suzuki et al., 2007, 2004) and speech and verbalization (Dileo \& Bradt, 2005), and significantly reduce agitation, anxiety, aggressiveness, irritability, delusions, apathy, aberrant motor activity and night-time disturbances (Choi, Lee, Cheong, Lee, 2009; Hicks-Moore, 2005; Raglio et al., 2008; Suzuki et al., 2004; Svansdottri \& Snaedal, 2006; Tuet \& Lam, 2006). Music has also been shown to produce a number of positive physiological effects for those with dementia including: increased melatonin levels, which contribute to a relaxed mood (Kumar, Tims, Xruess \& Mintester, 1999); and decreased levels of the stress indicator salivary chromogranin A 
(Suzuki et al, 2007, 2004). In terms of the specific effect that music has on quality of life (QOL), studies have found that music can promote greater feelings of belonging (Ebberts, 1994; Pollack \& Namazi, 1992; Rio, 2002) and enable those with dementia to appropriately interact with each other in a group setting (Clair \& Bernstein, 1990). In addition, music in the everyday lives of older people with dementia (i.e., not delivered though a therapeutic structure) can enhance wellbeing, social interaction, empowerment and control, and can encourage and support participation in activities (Sixsmith \& Gibson, 2007). A small number of studies have also highlighted how music can reduce levels of depression in those with dementia. For example, Ashida (2000) found that reminiscence music significantly reduced depressive symptoms in older people with dementia. Another study (viz., Myskja \& Nord, 2008) reported that two months after music therapy was reinstated at an aged care facility following a break of a few months, depression scores significantly decreased.

Evidently, there is a growing body of research documenting the positive effect of music in managing dementia. If the true efficacy of music as a therapeutic tool is to be evaluated, greater efforts should be directed at measuring the duration of effects. Of the limited longer-term studies undertaken, most typically show the effects to be relatively short-term. For example, studies report the dissipation of positive effects at one to four weeks post-intervention (Bruer, Spitznagel \& Cloninger, 2007; Svansdottri \& Snaedal, 2006; Tuet \& Lam, 2006). In a year-long study, comparing a group who received regular weekly music sessions with a group who received usual care, no significant differences were observed in terms of the severity, range and frequency of agitated behaviours over time (Ledger \& Baker, 2007). Similarly, Berger et al (2004) failed to find an effect of music on the behavioural and mental changes of those with dementia over two years. In contrast, however, some support for the 
longer-term effects of music is available. Improvements in behaviours such as delusions and apathy have been found one month post-intervention (Raglio et al., 2008). In another study, participants who received music therapy, once a week for two years, had significantly lower systolic blood pressure and maintained their physical and mental states better than those not receiving music (Takahashi \& Matsushita, 2006).

Despite the evidence that music has a therapeutic effect on the behaviour of those with dementia, there are strong methodological concerns regarding available studies and there are calls for more rigorous research (Boso, Politi, Barale \& Emanuele, 2006). Following a 2003 Cochrane Review (Vink, Birks, Bruinsma \& Scholten, 2005) such was the extent of these concerns that the authors felt unable to support claims about the efficacy of music therapy. Studies were criticised for failing to: randomize participants; conceal allocation of participants to treatment groups; ensure blinding of assessors; use standardized assessment tools; and establish longitudinal effects. Other reviews have criticised studies for employing insufficient sample sizes that make the findings difficult to generalise (Goodall \& Etters, 2005). The study described here sought to address some of these concerns by employing a randomized controlled trial with a cross-over design, which allowed an exploration of longer-term effects and had a sample size large enough to detect significant differences. Furthermore, analysis followed an Intention-To-Treat (ITT) principle so as to avoid the overestimation of clinical effectiveness associated with analysis which omits study drop-outs (Hollis \& Campbell, 1999, Kruse, Alper, Reust, Stevermer, Shannon \& Williams, 2002; Montori \& Guyatt, 2001). 
This study aimed to investigate the effect of a live music program on quality of life (QOL) and depression in older people with dementia. The study sought to answer the following questions:

1. What effect does a live music program have on QOL and depression for older people with dementia?

2. What is the duration of any effects of a live music program on QOL and depression for older people with dementia over a six-month period?

\section{Methods}

\section{Design}

A randomized controlled cross-over design, with a music intervention and a reading control group, was employed from October 2008 to March 2009 (see Figure 1). This methodology was employed because it: ensured a high level of equivalence among the participants exposed to the two treatments (Polit, Beck \& Hungler, 2001); saw no participant denied a potentially beneficial treatment; and allowed an examination of longer-term effects over a six-month period (Vink, Birks, Bruinsma \& Scholten, 2005). Ethical approval for the study was granted by the University human research ethics committee and a support statement was provided by the partner aged care organisation.

\section{[INSERT HERE Figure 1]}

\section{Setting}

Two mixed-gender aged care facilities were used to recruit participants. Site A had 164 residents and Site B had 94 residents. Both facilities were located north of Brisbane (Queensland Australia) and provided low and high (nursing home) care.

\section{Sample}


A sample of 40-50 participants, allowing for $10 \%$ attrition, was anticipated to ensure a statistical power of 0.90 . This estimation was based on the effect size (Cohen's d) of 0.67 calculated from Suzuki et al (2004) and by adopting an alpha level of .05 and employing the algorithm detailed in Senn (1993, p218). Aged care facility managers initially identified potential male and female participants, with formal enrolment based on residents having:

1. a confirmed diagnosis of early to mid stage dementia, OR probable dementia (i.e. a cognitive impairment level of 12-24 on the Mini Mental State Exam - Folstein, Folstein \& McHugh, 1975), OR features consistent with dementia of Alzheimer's type as per DSM-IV (American Psychiatric Association, 1994).

and

2. a documented behavioural history of agitation/aggression on nursing/ medical records within the last month

The study's biostatistician, who was blinded to the identity of potential participants, used a computer-generated program to conduct the randomization process. Informed consent was sought from next of kin and, where appropriate, participants themselves. All data collectors were blinded to group assignments.

\section{Intervention}

The music and reading groups ran for 40-minutes, three mornings a week (Monday, Wednesday and Friday) for eight weeks. Participants then 'crossed-over' into the opposite arm and the protocol was repeated for another eight weeks. A five-week 'washout' period was included between cross-over to reduce potential carryover effects (Ayalon, Gum, Feliciano \& Arean, 2006), being based on studies which have found the effects of a music intervention to dissipate at one to four weeks post- 
intervention (Bruer, Spitznagel \& Cloninger, 2007; Svansdottri \& Snaedal, 2006; Tuet \& Lam, 2006). Group music sessions were chosen over individual interventions as previous literature has shown these to be effective in providing interaction and feelings of belonging for those with dementia (Ebberts, 1994; Pollack \& Namazi, 1992; Rio, 2002). The maximum size of the group attending the music and reading sessions was 16 at Site A and nine at Site B. A participant attendance register was taken at the start of each session. Treatment fidelity was addressed through: 1 . development of a standardized procedures manual (Chambless \& Hollon, 1998); 2. musician and reading group facilitator training in delivery of the sessions and in working with older people with dementia; 3. a practice music session conducted in an alternative aged care facility to that used for the study; and 4. four random spot checks made by the research team.

The intervention was a live group music program delivered by two musicians. Each music session involved 30-minutes of musician-led familiar song singing (with guitar accompaniment) and 10-minutes of pre-recorded instrumental music for active listening. Live interactive music was preferred over pre-recorded music as it has been shown to be superior in the short-term treatment of apathy in participants with dementia (Holmes, Knights, Dean, Hodkinson \& Hopkins, 2006). Residents were encouraged to actively participate through singing, playing instruments and, where appropriate, movement. In addition, as research has shown that music interventions are most effective when using the personal musical preferences of participants (Dileo \& Bradt, 2005; Gerdner, 1997, 1999; Sung \& Chang, 2005), the repertoire selection for the music sessions was based primarily on: participants' musical preferences; musicians' repertoire knowledge; and the findings from the practice session. A set 
repertoire was established for each of the three sessions and repeated for the eight weeks.

The reading control sessions were led by a trained Research Assistant (RA) and were interactive in nature so as to mirror the music intervention. A range of reading/social activities were selected for the session including reading local news stories, short stories, telling jokes and undertaking quiz activities.

\section{Data Collection}

At baseline, mid-point and post-intervention participants were assessed on two primary outcome measures. Both measures were conducted by trained RAs blinded to the treatment groups at a time most convenient for the participant (i.e., any day of the week from 9am - 5pm). The RAs took the role as interviewer, taking the participants through the measures by asking them questions to elicit their response. All participants were able to verbalise their answers:

1. Dementia Quality of Life (DQOL) (Brod, Stewart, Sands \& Walton, 1999): a 29-item interview questionnaire consisting of five subscales and an optional single item, which assesses overall QOL in a single score. All 29 items are rated on two 5point scales (ranging from 'not at all' to 'a lot', and 'never' to 'very often') to measure participant's QOL. A mean score is computed for each subscale, with higher scores representing better QOL. The DQOL has been found to be reliable in people with dementia, with the test-retest reliability for the five subscales being reported from 0.64-0.90 and internal consistency reliability from 0.67-0.89 (Sloane, Zimmerman, Williams, Reed, Gill \& Preisser, 2005). In this study, the internal consistency (Cronbach’s alpha) of the subscales was between 0.62-0.87.

2. Geriatric Depression Scale (GDS) (Yesavage et al, 1983): a 15-item interview questionnaire requiring participants to record a 'yes/no' response to statements about 
themselves. An overall score is computed by summing all bolded responses, which are indicative of depression and worth one point. A score $>5$ is suggestive of depression and a score of $\geq 10$ is almost always indicative of depression. The GDS has been tested and used extensively, being found to have $92 \%$ sensitivity and $89 \%$ specificity when evaluated against diagnostic criteria (Kurlowicz, 1999). It has also been recommended as a valid instrument for assessing depression (Sansoni et al., 2007). When used in this study, the internal consistency of the scale (Cronbach's alpha) was 0.79 .

Participant's severity of dementia was assessed by trained and experienced RAs blinded to treatment groups at baseline and post-intervention on the Mini-Mental State Exam (MMSE) (Folstein, Folstein \& McHugh, 1975): a widely used cognitive screening instrument that provides a total score ranging from 0-30, with lower scores indicative of greater cognitive impairment. A range of demographic information (i.e. age; gender; dementia diagnosis; existing medical conditions etc) was also collected at baseline, as was participants' musical preferences and experiences using an adapted version of the Music Preference Questionnaire (Hartsock, 1982 as cited in Bulechek \& McCloskey, 1999).

\section{Data Analysis}

All data were entered and analysed using the Statistical Package for the Social Sciences Version 17.0 (SPSS Inc., Chicago, IL, USA). Prior to analysis, 20\% of the data were double-entered, with outliers and missing values screened to establish data entry accuracy and consistency. Basic frequencies were established for all participant demographics, MMSE scores and outcome measures. Internal consistency of the measures was assessed through the computation of Cronbach's coefficient alpha $(\alpha)$. A series of $t$-tests were undertaken to ascertain whether randomization had been 
successful in a number of pre-test values. In addition, a paired samples $t$-test was run to compare MMSE scores over time, and two one-way ANOVAs were undertaken to compare MMSE scores between intervention and control groups at baseline and postintervention.

Following a Missing Values Analysis, which indicated data to be Missing At Random (MAR), an 'Intention To Treat' (ITT) analysis, in which all randomized participants were included in the final analysis $(n=47)$, was undertaken. A multiple imputation method was applied to missing values in the outcome measures using NORM (Schafer, 1999). Five multiple imputed datasets and one overarching imputed dataset were computed. To verify the results, parallel analysis was undertaken on the overarching multiple imputed dataset and: an imputed dataset with missing value case mean substitution; and the original dataset with missing values. No differences were observed in analysis and, thus, the reported outcome measure $p$-values are from the overarching imputed dataset. Two sub-analyses were also undertaken on the multiple imputed dataset for participants who: attende $\underline{a} 50 \%$ of music sessions ( $n=24-14$ receiving music in the first arm and 10 in the second arm); and had scores $>5$ on the GDS ( $n=12$ - five receiving the first music intervention and seven the control). All reported significant differences are at the p-value of 0.05 and, where sphericity was not assumed, the Greenhouse Geisser $p$-value is given.

The generalised linear method (GLM) of analysis advocated by Senn (1993) was employed to explore main effects; investigating the treatment effect after the period and carry-over effects had been tested. This saw: 1. oneway ANOVAs to test for differences in music and control group scores at baseline, mid-point and postintervention; 2. repeated measures ANOVAs, with Bonferroni pairwise comparisons, 
to explore significant differences over time, regardless of group; 3. repeated measures ANOVAs to explore interaction effects of the intervention group by time-point.

\section{Results}

Sixty-nine residents were assessed for eligibility and 47 were formally enrolled into the research (see Figure 2). Randomization proved successful as there were no significant differences between the first music and control groups in terms of: age ( $p=0.944)$; gender ( $p=0.597)$; length of time living in the facility ( $p=0.490)$; dementia diagnosis ( $p=0.147)$; use of chemical restraint to manage disruptive behaviour ( $p=0.645)$; importance of music in life prior to living in the facility ( $p=0.437)$; and musical experience/background ( $p=0.337$ ). Missing values analysis found that $8.7 \%$ of data was Missing At Random (MAR) in the outcome measures (8.7\% in DQOL \& $8.6 \%$ in GDS).

\section{[INSERT HERE Figure 2]}

\section{Sample Characteristics}

The majority of participants were: female (70.2\%); aged 75-94 (87.2\%); widowed (74.5\%); and educated at secondary school level (69.6\%). Over half of participants had lived in the facility for more than one but less than four years (56.5\%) and it was most common for participants to live in the Special Care Unit (SCU) (38.3\%) or low care (34.0\%). One in four had high blood pressure (45.7\%) or osteoarthritis (43.5\%), while one in three had coronary heart disease, depression (30.4\% respectively) and/or diabetes $(28.3 \%)$. The vast majority $(87.0 \%)$ of participants were visually impaired and, in terms of mobility requirements, it was most common for participants to be in a wheelchair (38.3\%), be mobile (36.2\%) or use a wheelie-walker/frame $(31.9 \%)$. Verbal agitation was noted in approximately $85 \%$ of care plans (see Table 1).

[INSERT HERE Table 1] 
At baseline, the mean MMSE score was 16.51 (SD $=6.737$, middle stage dementia). There was no significant difference in MMSE scores from baseline to postintervention $(p=0.231)$ or in the MMSE scores of the music and control groups at baseline $(p=0.399)$ or post-intervention $(p=0.849)$.

Participant mean scores on the DQOL and GDS suggested consistently low levels of depression and good QOL. Mean global QOL scores for all participants, at all time-points, clustered around the mid-point of the scale (3), thereby equating to 'good' overall ratings. On the GDS, although participant scores ranged from 0 to 14, overall mean scores at all time-points were below five (range: 3.38 - 4.47), indicating relatively low levels of depression.

\section{Significant Main Effects}

One significant finding emerged from the main analysis, namely that there was a significant difference in the mid-point QOL belonging scores between the music and reading groups $(F(1,45)=6.672, p<0.05)$. Specifically, participants who experienced the reading control first reported higher feelings of belonging (3.61) than those who experienced the music first (3.17). Means showed that when the first reading group crossed-over into the music group their scores decreased (3.61 to 3.46), whereas when the first music group crossed-over into the reading group, their scores increased (3.17 to 3.57) (see Table 2).

\section{Sub-analyses}

In the two sub-analyses undertaken, two significant findings emerged:

1. In the sub-analysis of participants attending $\geq 50 \%$ of music sessions in either arm one or two of the study ( $n=24$ ), there was a significant improvement in QOL selfesteem scores over time, regardless of group $(F(2,46)=4.471, p<0.05)$. Specifically, 
there was a significant improvement $(p<0.05)$ in scores from mid-point $(3.36)$ to postintervention (3.75).

2. In the sub-analysis of participants who had scores of $>5$ on the GDS $(n=12)$, there was a significant difference in depression scores over time $(F(2,22)=8.129, p<0.01)$. Specifically, depression scores decreased (8.25, 6.50, 4.42 respectively), being more noticeable for those experiencing the music sessions $(9.00,6.20,4.40)$ compared to the reading group $(7.71,6.71,4.43)$. GLM analysis indicated the findings to be independent of carry-over effects as there was a non-significant order by treatment interaction $(p=0.649)$.

\section{[INSERT HERE Table 2]}

\section{Discussion}

In understanding the overarching non-significant findings, a number of explanations may be postulated. Firstly, it may be that music does not have a greater therapeutic effect than other group activities. Previous research has shown that the well-being of aged care residents can be improved through a range of stimulating and enjoyable activities (Cohen-Mansfield \& Werner, 1997), and so it may be that both the music and reading groups offered greater engagement than normal, routine activities. That said, however, the specific positive benefits of music has been consistently reported in a growing body of evidence (Brotons, Koger \& Pickett-Cooper, 1997; Bruer, Spitznagel \& Cloninger, 2007; Choi, Lee, Cheong \& Lee, 2009; Dileo \& Bradt, 2005; Goodall \& Etters, 2005; Hicks-Moore, 2005; Kumar, Tims, Xruess \& Mintester, 1999; Raglio et al., 2008; Suzuki et al, 2007, 2004; Svansdottri \& Snaedal, 2006; Tuet \& Lam, 2006). It was also visibly tangible in the observations we made during the music sessions how much the participants specifically enjoyed this activity. It may be beneficial, therefore, for future studies to include a third group of participants 
undergoing usual care. Secondly, it may be that any positive effects of the music intervention were short-term and dissipated soon after the sessions ended. This idea is in line with previous research that has typically shown the immediate effects of music for people with dementia (Bruer, Spitznagel \& Cloninger, 2007; Svansdottri \& Snaedal, 2006; Tuet \& Lam, 2006). Finally, the results may be a product of the low baseline scores on the outcome measures. For instance, in our study the proportion of participants with scores suggestive of increased depressive symptoms on the GDS (25.5\%) was much lower than prevalence rates reported in a large Australian survey of 1250 participants who were able to cognitively respond (41.1\%) (Snowden \& Flemming, 2008). Previous researchers have identified low scoring of behaviours as possible reasons for non-significant findings, advocating that future research would benefit from greater screening of participants (Ledger \& Baker, 2007; Nugent, 2000). We fully endorse these views and urge future researchers to consider greater screening methods to assess baseline levels for measures such as agitation and depression, prior to study commencement.

The finding that, at midpoint, participants in the reading group reported higher feelings of belonging than those in the music group may be due to differences in the delivery of the sessions. The music intervention was very structured and followed a set pattern each time; a point considered important to ensure treatment fidelity. As such, the music sessions were very much musician-led. The reading sessions, in contrast, were more organic in structure and could include a range of activities such as quizzes and discussions about the past. In this sense, the facilitator of the reading sessions may have stimulated greater individual involvement and created greater feelings of group coherence and belonging. This finding, that a reading activity created greater feelings of belonging than a music activity, should be investigated 
further. Such studies should employ a similar control group so as to determine if our results are replicable.

The finding that self-esteem scores significantly increased over-time for participants who attende $\$ 50 \%$ of music sessions in either arm of the study, regardless of group, arguably makes intuitive sense. It seems plausible that the more sessions a participant attended, the more familiar they became with the format and structure, thus contributing to greater feelings of mastery, control and self-esteem. Previous research from a number of studies offer support for this notion. For instance, music in the everyday lives of older people with dementia has been shown to enhance empowerment and control (Sixsmith \& Gibson, 200) and regular, one to three-weekly music therapy sessions have been found to affect levels of agitation (Brotons, Koger \& Pickett-Cooper, 1997; Clair \& Bernstein, 1990; Ebberts, 1994; Suzuki et al., 2004). More research is needed to determine if improvements in indicators, such as QOL, can also be specifically improved through regular group activities, and not just those involving music.

Finally, the finding that depression scores, for those participants with scores on the GDS that were suggestive of depressive symptoms, decreased significantly over time, most noticeably for the music group, is perhaps of most interest. Firstly, it suggests that both music and reading group activities can do much to alleviate depressive symptoms in those individuals with likely depression. However, as only a few studies have previously highlighted how music can reduce levels of depression in those with dementia (Ashida, 2000; Myskja \& Nord, 2008), it is difficult to make an evaluation of efficacy. Finally, the results provide further support for greater screening of participants prior to study commencement. When scores on the GDS were suggestive of depression, although based on a smaller sample size $(n=12)$, a 
statistically significant result emerged. This provides some evidence that low scores on outcome measures may have influenced the lack of overall non-significant results.

\section{Conclusion}

Participation in a 40-minute live music intervention, three-times a week for eight weeks, did not significantly affect levels of depression and QOL in older people with dementia. There was also no evidence to indicate that the therapeutic use of live music was more effective than a group reading activity. That said, however, results did suggest that both the music and reading group activities offered opportunities to improve sense of belonging, self-esteem and depressive symptoms in some older people with dementia. Furthermore, there was no evidence of adverse affects after involvement in either activity for participants. Further research into the specific benefits of regular, facilitation-based group engagement approaches with older people with dementia, particularly those demonstrating greater depressive symptoms, is needed to understand these findings further and determine their practical application. 


\section{References}

Access Economics. (2009). Keeping dementia front of mind: Incidence and prevalence 2009-2050. Alzheimer’s Australia: Canberra.

American Psychiatric Association. (1994). Diagnostic and Statistical Manual of Mental Disorders (4 ${ }^{\text {th }}$ ed.). USA: American Psychiatric Association.

Ashida, S. (2000). The effect of reminiscence music therapy sessions on changes in depressive symptoms in elderly persons with dementia. Journal of Music Therapy, 37, 170-182.

Ayalon, L., Gum, A.M., Feliciano, L. \& Arean, P.A. (2006). Effectiveness of nonpharmacological interventions for the management of neuropsychiatric symptoms in patients with dementia. Archives of International Medicine, 166, 2182-2188.

Berger, G., Bernhardt, T., Schramm, U., Müller, R., Landsiedel-Anders, S., Peters, J., Kratzsch, T. \& Frolich, L. (2004). No effects of a combination of caregivers support group and memory training/music therapy in dementia patients from a memory clinic population. International Journal of Geriatric Psychiatry, 19(3), 223-231.

Boso, M., Politi, P., Barale, F. \& Emanuele, E. (2006). Neurophysiology and neurobiology of the musical experience. Functional Neurology, 21(4), 187-191.

Brod, B., Stewart, A., Sands, L. \& Walton, P. (1999). Conceptualization and measurement of quality of life in dementia: Dementia quality of life instrument (DQoL). The Gerontologist, 39, 25-35.

Brotons, M., Koger, S.M. \& Pickett-Cooper, P. (1997). Music and dementias: A review of the literature. Journal of Music Therapy, 34, 204-245. 
Bruer, R.A., Spitznagel, E. \& Cloninger, C,R. (2007). The Temporal Limits of Cognitive Change form Music Therapy in Elderly Persons with Dementia or Dementia-Like Cognitive Impairment: A randomized controlled trial. Journal of Music Therapy, 44(4), 308-328.

Bulechek, G.M., McCloskey, J.C. (1999). Nursing Interventions: Effective Nursing Treatments (3rd ed.). Philadelphia: W.B. Saunders Company.

Chambless, D. \& Hollon, S.D. (1998). Defining empirically supported therapies. Journal of Consulting and Clinical Psychology, 66(1), 7-18.

Choi, A., Lee, M.S., Cheong, W. \& Lee, J. (2009). Effects of group music intervention on behavioural and psychological symptoms in patients with dementia: a pilot-controlled trial. International Journal of Neuroscience, 119, 471-481.

Clair, A.A. \& Bernstein, B. (1990). A preliminary study of music therapy programming for severely regressed persons with Alzheimer's-type dementia. The Journal of Applied Gerontology, 9(3), 299-311.

Cohen-Mansfield, J. \& Mintzer, J.E. (2005). Time for change: The role of nonpharmacological interventions in treating behaviour problems in nursing home residents with dementia. Alzheimer Disease and Associated Disorders, 19(1), 37-40.

Cohen-Mansfield, J., \& Werner, P. (1997). Management of verbally disruptive behaviours in nursing home residents. Journal of Gerontology: Medical Sciences, 52A(6), 369-377.

Crystal, H.A., Grober, E. \& Masur, D. (1989). Preservation of musical memory in Alzheimer's disease. Journal of Neurology, Neurosurgery, and Psychiatry, 52, 1415-1416. 
Dileo, C. \& Bradt, J. (2005). Medical Music Therapy: A meta-analysis and agenda for future research. Jeffrey Books: NJ, USA.

Ebberts, A.G. (1994). The effectiveness of three types of music therapy interventions with persons diagnosed with probable dementia of the Alzheimer's type who display agitated behaviours. Unpublished master’s thesis, University of Kansas, USA.

Evans, D., Wood, J., and Lambert, L. (2003). Patient injury and physical restraint devices: A systematic review. Journal of Advanced Nursing, 41(3), 274-282.

Ferri, C.P., Prince, M., Brayne, C., Brodaty, H., Fratiglioni, L., Ganguli, M., Hall, K., Hasegawa, K., Hendrie, H., Huang, Y., Jorm, A., Mathers, C., Menezes, P.R., Rimmer, E. \& Scazufca, M. (2005). Global prevalence of dementia: a Delphi consensus study. Lancet, 366(9503): p. 2112-2117.

Folstein, M., Folstein, S. \& McHugh, P. (1975). Mini-mental state. Journal of Psychiatric Research,12, 189-198.

Gerdner, L. (1997). An individualized music intervention for agitation. Journal of the American Psychiatric Nurses Association, 3(6), 177-184.

Gerdner, L.A. (1999). Individualized music intervention protocol. Journal of Gerontological Nursing, 25, 10-16.

Goodall, D. \& Etters, L. (2005). The therapeutic use of music on agitated behaviour in those with dementia. Holistic Nursing Practice, 19(6), 258-262.

Hicks-Moore, S.L. (2005). Relaxing music at mealtime in nursing homes: Effects on agitated patients with dementia. Journal of Gerontological Nursing, 31(12 ), 2632. 
Holmes, C., Knights, A., Dean, C., Hodkinson, S. \& Hopkins, V. (2006). Keep music live: Music and the alleviation of apathy in dementia subjects. International Psychogeriatrics, 18(4), 623-630.

Hollis, S. \& Campbell, F. (1999). What is meant by intention to treat analysis? Survey of published randomized controlled trials. British Medical Journal, 319, 670674.

Hughes, J.C. (2002). Ethics and the psychiatry of old age. In Psychiatry in the Elderly, Jacoby R, Oppenheimer C (eds). Oxford University Press: Oxford; 863-895.

Kruse, R.L., Alper, B.S., Reust, C., Stevermer, J.J., Shannon, S. \& Williams, R. (2002). Intention-to-treat analysis: Who is in? Who is out? The Journal of Family Practice, 51(11), 969-971.

Kumar, A., Tims, F, Xruess, D.G. \& Mintester, M.J. (1999). Music therapy increases serum melatonin levels in patients with Alzheimer's disease. Alternative Therapies in Health Medicine, 5, 49-57.

Kurlowicz, L. (1999). The Geriatric Depression Scale (GDS). The Hartford Institute for Geriatric Nursing, Division of Nursing, New York University http://consultgerirn.org/topics/depression/want_to_know_more.

Ledger, A.J. \& Baker, F.A. (2007). An investigation of long-term effects of group music therapy on agitation levels of people with Alzheimer's Disease. Aging \& Mental Health, 11(3), 330-338.

Leibovici, A., (2009). Principles of geriatric psychopharmacology. In Psychiatry in long-term care, W.E. Reichman \& P.R. Katz (eds). New York: Oxford, 289-310. Montori, V.M. \& Guyatt, G.H. (2001). Intention-to-treat principle Canadian Medical Association, 165(10), 1339-1341. 
Myskja, A. \& Nord, P.G. (2008). 'The day the music died': A pilot study on music and depression in a nursing home. Nordic Journal of Music Therapy, 17(1), 3041.

Nugent, N. (2000). The effects of live versus taped preferred songs on individuals with dementia of the Alzheimer's type displaying agitated behaviours. Unpublished master's thesis, University of Melbourne, Australia.

Polit, D., Beck, D. \& Hungler, B. (2001). Essentials of nursing research: Methods, appraisal, and utilization (5th ed.). Philadelphia: Lippincott Williams \& Wilkins.

Pollack, N.J. \& Namazi, K.H. (1992). The effect of music participation on the social behaviour of Alzheimer's disease patients. Journal of Music Therapy, 29, 54-67.

Raglio, A., Bellelli, G., Traficante, D., Gianotti, M., Ubezio, M.C., Villani, D. \& Trabucchi, M. (2008). Efficacy of music therapy in the treatment of behavioural and psychiatric symptoms of dementia. Alzheimer's Disease and Associated Disorders, 22(2),158-162.

Rio, R. (2002). Improvisation with the elderly: Moving from creative activities to process-oriented Therapy. The Arts in Psychotherapy, 29, 191-201.

Robinson, L., Hutchings, D., Dickinson, H.O., Corner, L., Beyer, F., Finch, F., Hughes, J., Vanoli, A., Ballard, C. \& Bond, J. (2007). Effectiveness and acceptability of non-pharmacological interventions to reduce wandering in dementia: A systematic review. International Journal of Geriatric Psychiatry, 22, 9-22.

Sansoni, J., Marosszeky, N., Jeon, Y-H., Chenoweth, L., Hawthorne, G., King, M., Budge, M., Zapart, S., Sansoni, E., Senior, K., Kenny, P. \& Low, L. (2007). Final Report: Dementia Outcomes Measurement Suite Project. Centre for Health Service Development. University of Wollongong: Australia. 
Schafer, J.L. (1999). NORM: Multiple imputation of incomplete multivariate data under a normal model, version 2.

Senn, S. (1993). Cross-over trials in clinical research. Chichester: Wiley.

Sink K, M., Holden, K.F. \& Yaffe, K. (2005). Pharmacological treatment of neuropsychiatric symptoms of dementia: A review of the evidence. Journal of the American Medical Association, 293(5), 596-608.

Sixsmith, A. \& Gibson, G. (2007). Music and the wellbeing of people with dementia. Ageing and Society, 27, 127-145.

Sloane, P., Zimmerman, S., Williams, C., Reed, P., Gill, K. \& Preisser, J. (2005). Evaluating the quality of life of long-term care residents with dementia. The Gerontologist, 45(1), 37-49.

Snowdon J \& Fleming R. (2008). Recognising depression in residential facilities: An Australian challenge. International Journal of Geriatric Psychiatry, 23, 295-300.

Sung, H. \& Chang, A.M. (2005). Use of preferred music to decrease agitated behaviours in older people with dementia: A review of the literature. Journal of Clinical Nursing, 14, 1133-1140.

Suzuki, M., Kanamori, M., Nagasawa, S., Tokiko, I. \& Takayuki, S. (2007). Music therapy-induced changes in behavioural evaluations, and saliva chromogranin A and immunoglobulin A concentrations in elderly patients with senile dementia. Geriatrics and Gerontology International, 7, 61-71.

Suzuki, M., Kanamori, M., Watanabe, M., Nagasawa, S., Kojima, E., Ooshiro, H. \& Nakahara, D. (2004). Behavioural and endocrinological evaluation of music therapy for elderly patients with dementia. Nursing and Health Sciences, 6,1118. 
Svansdottri, H.B. \& Snaedal, J. (2006). Music therapy in moderate and severe dementia of Alzheimer's type: A case-control study. International Psychogeriatrics,18(4), 613-621.

Takahashi, T. \& Matsushita, H. (2006). Long-term effects of music therapy on elderly with moderate/severe dementia. Journal of Music Therapy, 43(4), 317-333.

Tuet, R.W.K. \& Lam, L.C.W. (2006). A preliminary study of the effects of music therapy on agitation in Chinese patients with dementia. Hong Kong Journal of Psychiatry, 16(3), 87-89.

Vink, V., Birks, J., Bruinsma, M. \& Scholten, R. (reprint 2005). Music therapy for people with dementia. This is a reprint of a Cochrane review, prepared and maintained by The Cochrane Collaboration and published in The Cochrane Library 2005, Issue 3.

Yesavage, J. A., Brink, T. L., Rose, T. L., Lum, O., Huang, V., Adey, M. B. \& Leirer, V.O. (1983). Development and validation of a geriatric depression screening scale: A preliminary report. Journal of Psychiatric Research, 17, 37-49. 
Figure 1 Study Design

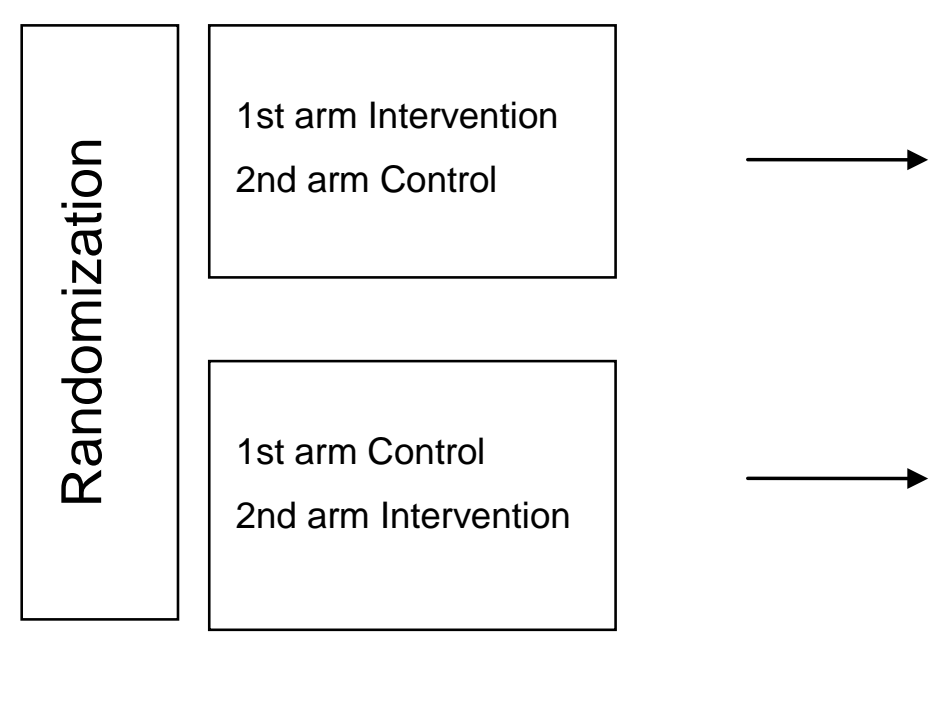

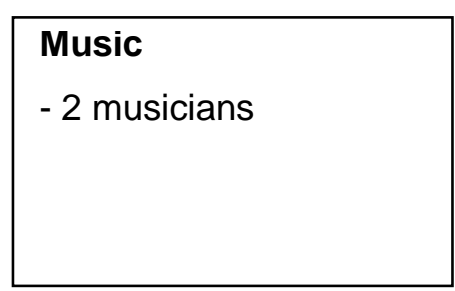

\section{Reading Control}

- 1 RA facilitator

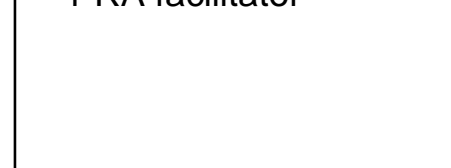

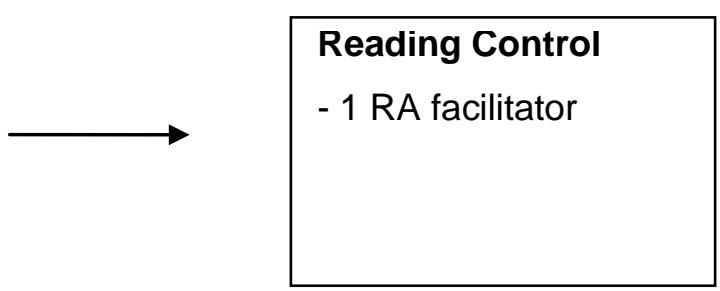

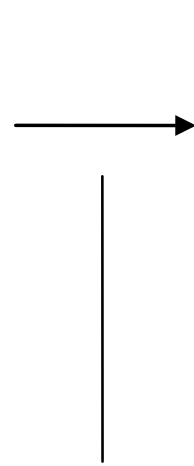

Mid-point DQOL

\section{Data Collection Points}

\begin{tabular}{ll}
\hline Research Assistant: & MMSE \\
& GDS \\
& DQOL
\end{tabular}

Facility managers/Next of Kin/Project Manager:

Demogs 
Figure 2 Flow chart of participants' progress through study

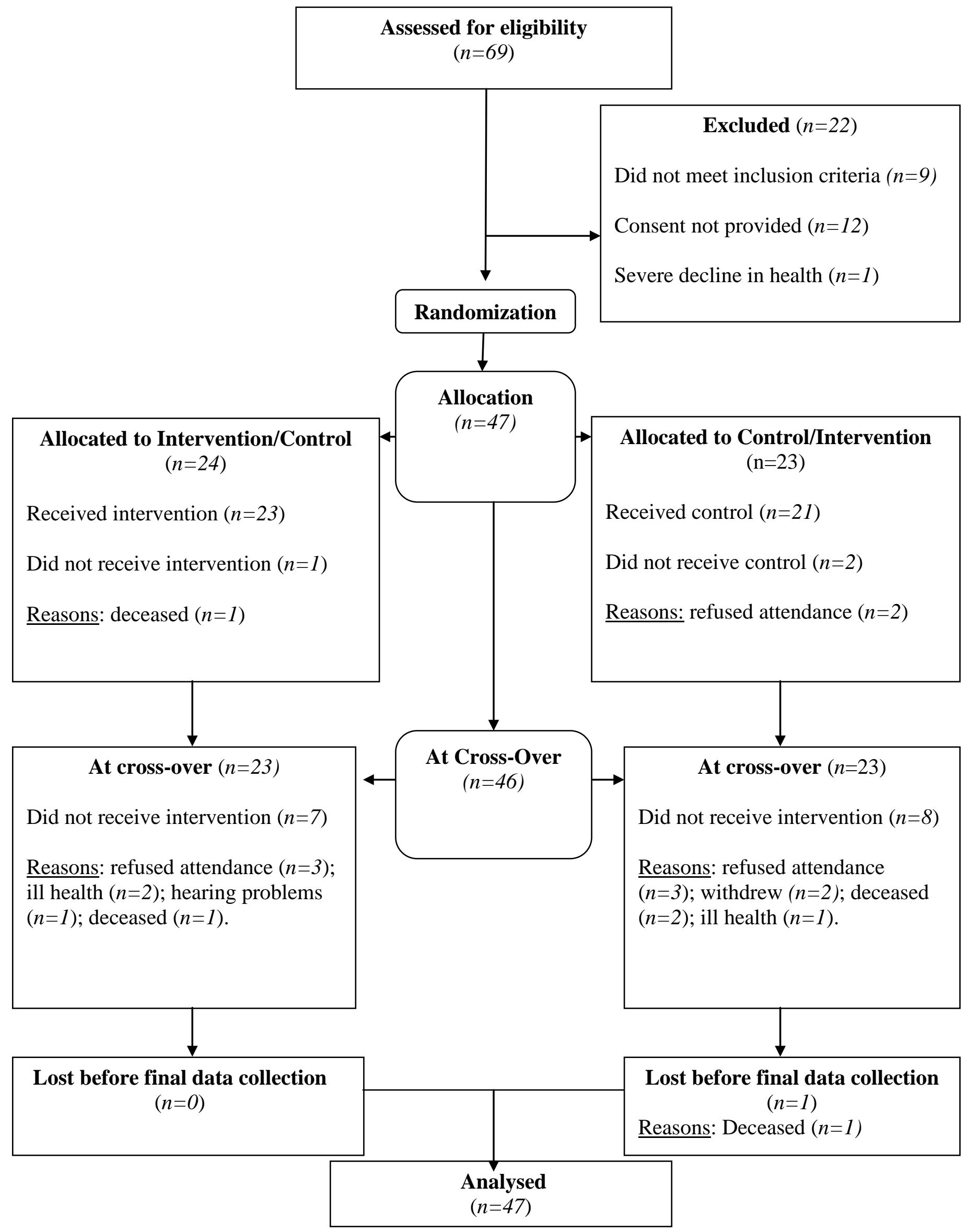


Table 1 Sample Characteristics

\begin{tabular}{|c|c|c|c|}
\hline & & (n) & (\%) \\
\hline \multirow{2}{*}{ Gender $(n=47)$} & Female & 33 & 70.2 \\
\hline & Male & 14 & 29.8 \\
\hline \multirow{4}{*}{ Age $(n=47)$} & $65-74$ & 3 & 6.4 \\
\hline & $75-84$ & 13 & 27.7 \\
\hline & $85-94$ & 28 & 59.6 \\
\hline & $95+$ & 3 & 6.4 \\
\hline \multirow{4}{*}{ Marital Status $(n=47)$} & Single & 1 & 2.1 \\
\hline & Married & 9 & 19.1 \\
\hline & Divorced & 2 & 4.3 \\
\hline & Widowed & 35 & 74.5 \\
\hline \multirow{4}{*}{ Highest level of education $(n=46)$} & Primary & 6 & 13.0 \\
\hline & Secondary & 32 & 69.6 \\
\hline & Vocational & 7 & 15.2 \\
\hline & University & 1 & 2.3 \\
\hline \multirow{5}{*}{ Time lived in facility $(n=46)$} & $<3$ months & 1 & 2.2 \\
\hline & 3 months - less $1 \mathrm{yr}$ & 9 & 19.6 \\
\hline & $1 y r-l e s s 4 y r s$ & 26 & 56.5 \\
\hline & 4 yrs - less 7 yrs & 7 & 15.2 \\
\hline & $7 y r s-l e s s 10 y r$ & 3 & 6.5 \\
\hline \multirow{3}{*}{ Level of care in facility $(n=47)$} & Low (Assistive) & 16 & 34.0 \\
\hline & High (Nursing Home) & 13 & 27.7 \\
\hline & SCU & 18 & 38.3 \\
\hline \multirow{8}{*}{ Comorbidities $(n=46)$} & Arthritis & 4 & 8.7 \\
\hline & Coronary Heart Disease & 14 & 30.4 \\
\hline & COPD & 10 & 21.7 \\
\hline & Osteoarthritis & 20 & 43.5 \\
\hline & High blood pressure & 21 & 45.7 \\
\hline & Diabetes & 13 & 28.3 \\
\hline & Stroke & 10 & 21.7 \\
\hline & Depression & 14 & 30.4 \\
\hline \multirow{6}{*}{ Sensory Deficit $(n=46)$} & Vision & 40 & 87.0 \\
\hline & Hearing & 29 & 63.0 \\
\hline & Touch & 2 & 4.3 \\
\hline & Tingling & 1 & 2.2 \\
\hline & Numbness & 1 & 2.2 \\
\hline & Pain & 20 & 43.5 \\
\hline \multirow{5}{*}{ Mobility Requirements ( $n=47)$} & Mobile & 17 & 36.2 \\
\hline & Walking stick & 3 & 6.4 \\
\hline & Wheelie walker/frame & 15 & 31.9 \\
\hline & Wheelchair & 18 & 38.3 \\
\hline & Chairfast & 2 & 4.3 \\
\hline \multirow{4}{*}{ Disruptive Behaviours $(n=46)$} & Physical aggression & 9 & 19.6 \\
\hline & Verbal aggression & 17 & 37.0 \\
\hline & Physical agitation & 27 & 58.7 \\
\hline & Verbal agitation & 39 & 84.8 \\
\hline \multirow{6}{*}{ Regular Medication $(n=46)$} & Antipsychotic & 9 & 19.6 \\
\hline & Antianxiety & 5 & 10.9 \\
\hline & SSRIS/SNRIS & 9 & 19.6 \\
\hline & Antidepressant & 4 & 8.7 \\
\hline & Antiepileptic & 1 & 2.2 \\
\hline & Analgesic & 29 & 63.0 \\
\hline
\end{tabular}


Table 2 Mean and $95 \%$ confidence intervals $(95 \% \mathrm{Cl})$ of baseline, mid-point and post-intervention DQOL and GDS scores by music intervention and control groups

\begin{tabular}{|c|c|c|c|c|c|c|c|}
\hline & \multicolumn{2}{|c|}{ Baseline } & \multicolumn{2}{|c|}{ Mid-point } & \multicolumn{2}{|c|}{ Post-intervention } \\
\hline & & Mean & $(95 \% \mathrm{Cl})$ & Mean & $(95 \% \mathrm{Cl})$ & Mean & $(95 \% \mathrm{Cl})$ \\
\hline \multirow{2}{*}{$\begin{array}{l}\text { DQOL: } \\
\text { Overall }\end{array}$} & Music & 3.29 & $\begin{array}{l}(2.95, \\
3.63)\end{array}$ & 3.38 & $\begin{array}{l}(2.93, \\
3.82)\end{array}$ & 3.25 & $\begin{array}{l}(2.85, \\
3.65)\end{array}$ \\
\hline & Control & 3.57 & $\begin{array}{l}(3.22, \\
3.91)\end{array}$ & 3.09 & $\begin{array}{l}(2.74, \\
3.43)\end{array}$ & 3.22 & $\begin{array}{l}(2.85 \\
3.59)\end{array}$ \\
\hline \multirow{2}{*}{$\begin{array}{c}\text { DQOL: } \\
\text { Self-esteem }\end{array}$} & Music & 3.52 & $\begin{array}{l}(3.20, \\
3.84) \\
\end{array}$ & 3.45 & $\begin{array}{l}(3.14, \\
3.75) \\
\end{array}$ & 3.52 & $\begin{array}{l}(3.20, \\
3.85)\end{array}$ \\
\hline & Control & 3.37 & $\begin{array}{l}(3.12, \\
3.62)\end{array}$ & 3.21 & $\begin{array}{l}(2.97, \\
3.45)\end{array}$ & 3.46 & $\begin{array}{l}(3.13, \\
3.78)\end{array}$ \\
\hline \multirow{2}{*}{$\begin{array}{l}\text { DQOL: } \\
\text { Positive } \\
\text { Affect }\end{array}$} & Music & 3.61 & $\begin{array}{l}\text { (3.31, } \\
3.91)\end{array}$ & 3.35 & $\begin{array}{l}(3.06, \\
3.64)\end{array}$ & 3.51 & $\begin{array}{l}(3.15, \\
3.86)\end{array}$ \\
\hline & Control & 3.52 & $\begin{array}{l}(3.29, \\
3.75)\end{array}$ & 3.50 & $\begin{array}{l}(3.23, \\
3.77)\end{array}$ & 3.39 & $\begin{array}{l}(3.12 \\
3.67)\end{array}$ \\
\hline \multirow{2}{*}{$\begin{array}{c}\text { DQOL: } \\
\text { Absence of } \\
\text { Negative } \\
\text { Affect }\end{array}$} & Music & 4.00 & $\begin{array}{l}(3.75, \\
4.26) \\
\end{array}$ & 3.96 & $\begin{array}{l}(3.70, \\
4.23) \\
\end{array}$ & 4.15 & $\begin{array}{l}(3.88, \\
4.42) \\
\end{array}$ \\
\hline & Control & 3.76 & $\begin{array}{l}(3.40 \\
4.12) \\
\end{array}$ & 3.85 & $\begin{array}{l}(3.57, \\
4.14) \\
\end{array}$ & 4.11 & $\begin{array}{l}(3.86, \\
4.37) \\
\end{array}$ \\
\hline \multirow{2}{*}{$\begin{array}{l}\text { DQOL: } \\
\text { Feelings of } \\
\text { Belonging }\end{array}$} & Music & 3.47 & $\begin{array}{l}(3.23, \\
3.71) \\
\end{array}$ & 3.17 & $\begin{array}{l}(2.92, \\
3.41) \\
\end{array}$ & 3.57 & $\begin{array}{l}(3.26, \\
3.88) \\
\end{array}$ \\
\hline & Control & 3.62 & $\begin{array}{l}(3.38, \\
3.86)\end{array}$ & 3.61 & $\begin{array}{l}(3.35 \\
3.87)\end{array}$ & 3.46 & $\begin{array}{l}(3.23, \\
3.69)\end{array}$ \\
\hline \multirow{2}{*}{$\begin{array}{l}\text { DQOL: Sense } \\
\text { of Aesthetics }\end{array}$} & Music & 3.87 & $\begin{array}{l}(3.58 \\
4.17) \\
\end{array}$ & 4.12 & $\begin{array}{l}(3.86, \\
4.38) \\
\end{array}$ & 3.78 & $\begin{array}{l}(3.46, \\
4.09) \\
\end{array}$ \\
\hline & Control & 4.00 & $\begin{array}{l}(3.72, \\
4.28)\end{array}$ & 3.80 & $\begin{array}{c}(3.44, \\
4.16)\end{array}$ & 3.83 & $\begin{array}{l}(3.54, \\
4.11)\end{array}$ \\
\hline \multirow{2}{*}{ GDS } & Music & 3.63 & $\begin{array}{l}(2.25 \\
5.00) \\
\end{array}$ & 4.38 & $\begin{array}{l}(3.30, \\
5.45) \\
\end{array}$ & 3.50 & $\begin{array}{l}(2.09, \\
4.91) \\
\end{array}$ \\
\hline & Control & 3.96 & $\begin{array}{l}(2.61, \\
5.30)\end{array}$ & 4.57 & $\begin{array}{l}(3.32, \\
5.81)\end{array}$ & 3.26 & $\begin{array}{l}(2.27 \\
4.25)\end{array}$ \\
\hline
\end{tabular}

Notes to table: Intention to treat analysis with a multiple imputation method $(n=47)$ 